\title{
Making Machining Process more Efficient by Optimising the Tool Replacement Regime
}

\author{
Cristina GAVRUS \\ Transilvania University of Brasov, Romania, cristina.gavrus@unitbv.ro
}

\begin{abstract}
As known, all industrial companies from all over the world are aiming at the main objective, as to maximize their profit. In order to reach this objective, companies use certain strategies, principles and techniques. An important strategy regards the optimisation of the available resources, including material, financial, human and informational resources. Companies must also pay an important attention to their technological processes that include certain machining processes for obtaining the products to be delivered to the market place. The present paper is focused on the optimisation of the cutting tool changing regime, which represents an important part of the lead time, in order to make the machining process more efficient. The core of the paper regards the optimisation of multi-tool life and machining parameters so that the time of tool change is diminished. The paper also includes two case studies that refers to drilling process using multi-tool machining.
\end{abstract}

Keywords

Tool replacement, multi-tool machining, machining parameters optimization, tool life, twist drill

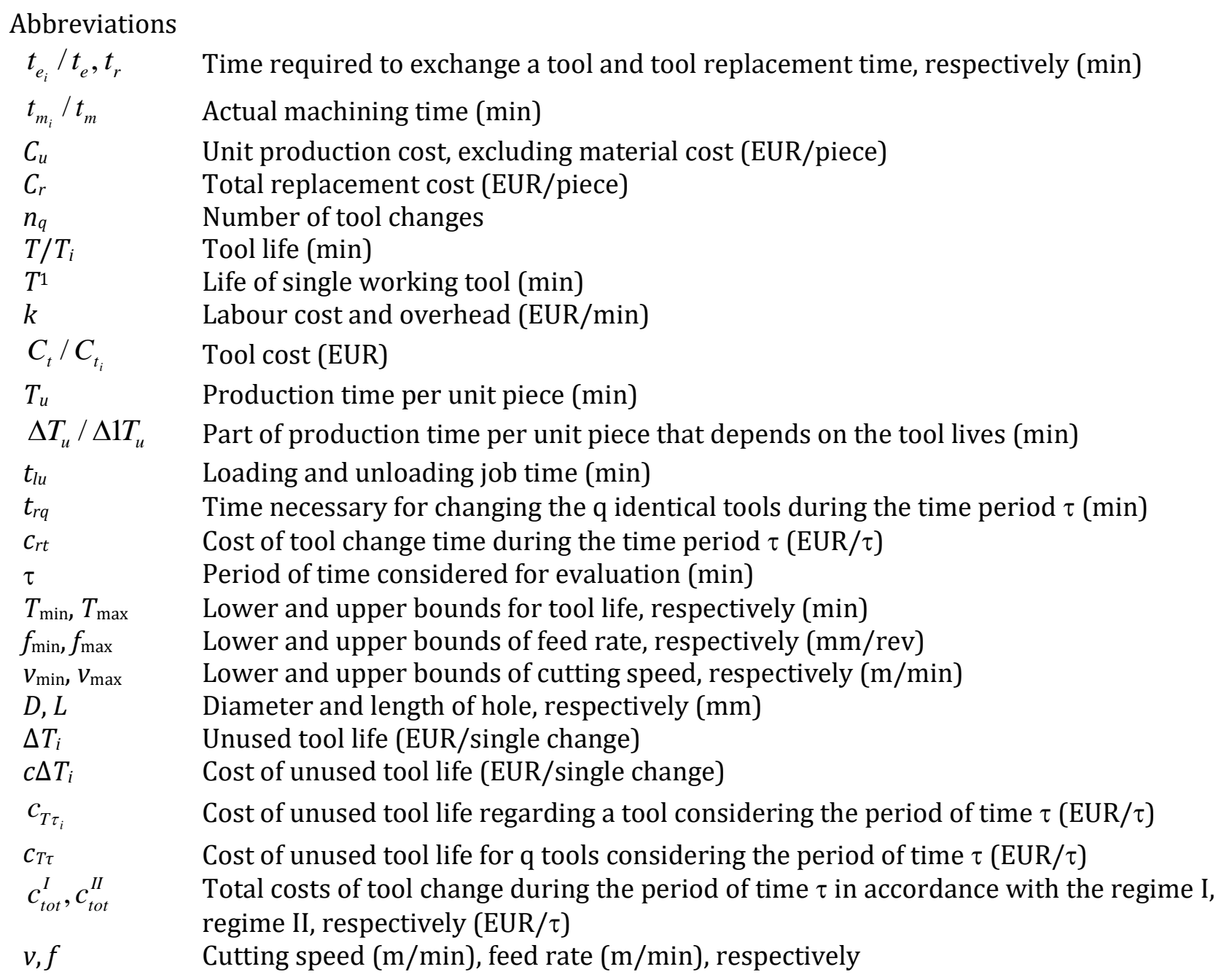




$\begin{array}{ll}q & \text { Number of tools } \\ C_{1}, x, y, z, m & \text { Constants of the tool life equation } \\ C_{F}, x_{F}, y_{F} & \text { Constants of the cutting force equation } \\ C_{M}, x_{M}, y_{M} & \text { Constants of the torsion moment equation } \\ F_{m}, P_{m} & \text { Maximum allowable cutting force }(\mathrm{N}), \text { maximum allowable cutting power }(\mathrm{kW})\end{array}$

\section{Introduction}

Nowadays, industrial process optimisation represents a major concern for the researchers from all over the world. This is aiming at production cost minimization or productivity maximization. The cost as well as the productivity are influenced by non-productive times, where the time related to changing and setting the tools come into a significant percentage. From this reason, it is useful to find modalities to reduce this time. Obviously, machining process automation is a good solution, but not enough. A good direction where solutions must be sought is the optimisation of tool replacement regime. The issue becomes even more interesting when talking about multi-tool machining. The present paper approaches the issue of tool replacement regime in case of multi-tool machining, aiming at machining process optimisation.

\section{Literature Review}

The issue of reducing the tool change time is related to machining parameters optimisation. Among the first scientific approaches papers $[1,2]$ must be mentioned. Then, many works have approached the machining parameters optimisation. Within the mathematical models regarding machining parameters optimisation there are found the times and costs related to the tool change [3-11]. The tool replacement time [6] can be expressed as follows:

$$
t_{r}=t_{e} \cdot \frac{t_{m}}{T}
$$

Considering equation (1), the cost of tool replacement time is given by:

$$
C_{r}=k \cdot t_{e} \cdot \frac{t_{m}}{T} .
$$

The cost of machining a piece can be expressed in the following way:

$$
C_{u}=t_{m} \cdot k+\frac{t_{m}}{T} \cdot t_{e} \cdot k+\frac{t_{m}}{T} \cdot C_{t} .
$$

Considering the above equations, the tool life has a great influence upon the machining cost and productivity. Equation (3) becomes the objective function in the majority of methods of machining parameters optimisation. For the correct solving of the problem, the objective function must be connected to a set of constraints. The tool life $T$ is most often integrated into optimisation mathematical models through the equation [3-11]:

$$
T=\frac{C_{1}}{v^{x} \cdot f^{y} \cdot d^{z}} .
$$

The values for $v, f$ and $d$ directly result and the value for $T$ indirectly results, in accordance with equation (4). For a correct optimisation, the influence of tools change upon costs and productivity of machining must be considered. With a view to highlighting the importance of tool replacement regime upon the machining process efficiency, an analysis regarding multi-tool machining is presented next.

\section{Impact of Tool Replacement Regime upon Machining Process Efficiency}

Considering that there are used q tools that simultaneously work and a period of time $\tau$, their replacement consumes the following non-productive time:

$$
t_{r q}=\tau \cdot \sum_{i=1}^{q} \frac{t_{e_{i}}}{t_{e_{i}}+T_{i}} .
$$

If all the tools are identical $\left(t_{e_{1}}=t_{e_{2}}=\ldots=t_{e_{q}}=t_{e}\right.$ and $\left.T_{1}=T_{2}=\ldots=T_{q}=T\right)$, the non-productive time was: 


$$
t_{r q}=\frac{\tau \cdot q \cdot t_{e}}{q \cdot t_{e}+T}
$$

and the cost related to this time was:

$$
c_{r \tau}=k \cdot t_{r q}
$$

\subsection{Tool replacement regimes}

The tools can be replaced into two main modalities (replacement regimes): I - every tool is replaced after its tool life ends or II - tools are replaced by tool groups, considering the minimum tool life. In case that tools are replaced by groups, there is a certain unused tool life that generates certain costs. Considering that a tool having $T_{i}$ tool life has an unused tool life $\Delta T_{i}$, the cost of this unused tool life is:

$$
c \Delta T_{i}=\frac{\Delta T_{i} \cdot C_{t_{i}}}{T_{i}} .
$$

The cost of unused tool life related to the period of time $\tau$ becomes (considering $t_{e_{1}}=t_{e_{2}}=\ldots=t_{e_{q}}=t_{e}$ ):

$$
c_{T \tau_{i}}=\frac{\tau}{q \cdot t_{e}+T_{\min }} \cdot \frac{\Delta T_{i} \cdot C_{t_{i}}}{T_{i}} ; c_{T \tau}=\frac{\tau}{q \cdot t_{e}+T_{\min }} \cdot \sum_{i=1}^{q} \frac{\Delta T_{i} \cdot C_{t_{i}}}{T_{i}} .
$$

Thus, it results that in case of the two tool replacement regimes, the total costs of tool change related to the period of time $\tau$ are:

- for the case of regime I, the cost is:

$$
c_{t o t}^{I}=k \cdot \tau \cdot t_{e} \cdot \sum_{i=1}^{q} \frac{1}{t_{e}+T_{i}}
$$

- for the case of regime II, the cost is:

$$
c_{t o t}^{I I}=\frac{\tau}{q \cdot t_{e}+T_{\min }} \cdot\left(q \cdot t_{e} \cdot k+\sum_{i=1}^{q} \frac{\Delta T_{i} \cdot C_{t_{i}}}{T_{i}}\right) .
$$

As it can be seen from the above equations, the tool life has a great influence upon the machining process efficiency. The greater the number of tools, the greater the influence.

\subsection{Tool life in case of multi-tool machining}

The unit production time can be modelled as the sum of the following elements $[9,10]$ :

$$
T_{u}=t_{m}+\sum_{i=1}^{q} \frac{t_{m_{i}}}{T_{i}} \cdot t_{e_{i}}+t_{l u} .
$$

The paper refers only to the part that is influenced by the tool change $\left(\Delta T_{u}\right)$ and it considers simultaneously machining a piece by $q$ identical tools (twist drills). In this case, it can be written:

$$
\begin{gathered}
t_{m_{1}}=t_{m_{2}}=\ldots=t_{m_{i}}=\ldots=t_{m_{q}}=t_{m} ; \\
t_{e_{1}}=t_{e_{2}}=\ldots=t_{e_{i}}=\ldots=t_{e_{q}}=t_{e} ; \\
T_{1}=T_{2}=\ldots=T_{i}=\ldots=T_{q}=\ldots T .
\end{gathered}
$$

Using the following equation for the cutting speed [11]:

$$
v=\frac{C_{v} \cdot D^{z 1}}{T^{m} \cdot f^{y 1}},
$$

the unit production time becomes:

where the constant $k_{0}$ is:

$$
\Delta T_{u}=k_{0} \cdot f^{y 1-1} \cdot T^{m}+k_{0} \cdot q \cdot f^{y 1-1} \cdot t_{e} \cdot T^{m-1},
$$

$$
k_{0}=\frac{\pi \cdot D \cdot L}{1000 \cdot C_{v} \cdot D^{z 1}} .
$$


Acting in the following manner:

$$
\frac{d \Delta T_{u}}{d T}=0,
$$

it is obtained:

$$
T=\frac{1-m}{m} \cdot q \cdot t_{e} .
$$

Considering single-tool machining, the following equation is obtained:

$$
T^{1}=\frac{1-m}{m} \cdot t_{e},
$$

that highlights that between the tool life of the same tool that works once alone $\left(T^{1}\right)$ and then in a set of $q$ tools $(T)$ there is the following connection:

$$
T=q \cdot T^{1} .
$$

Equation (20) leads to the impossibility of machining in case $q$ is too great.

Of course, the case described above is a hypothetic one. But this situation highlights a truth: more increase the tool life the greater the number of tools. It means that equations (20) and (22) must be considered. But the following question appears: which the limits for equations (20) and (22) can work are? This suggests that machining parameters optimisation is compulsory for multi-tool machining.

\section{Machining Parameters Optimisation}

Machining parameters optimisation supposes designing a mathematical model containing an objective function and a series of technical constraints.

\subsection{Objective function}

Taking into consideration the part of the equation (12) that depends on the tool life and considering a machining process using $q$ identical tools (that simultaneously work) the objective function is:

$$
\Delta 1 T_{u}=t_{m}+q \cdot \frac{t_{m}}{T} \cdot t_{e}
$$

or

$$
\Delta 1 T_{u}=\frac{\pi \cdot D \cdot L}{1000 \cdot v \cdot f} \cdot\left(1+\frac{q \cdot t_{e}}{T}\right) .
$$

Considering equation (16), the objective function becomes:

$$
\operatorname{Min} \Delta 1 T_{u}=\operatorname{Min}\left[\frac{\pi \cdot D \cdot L}{1000 \cdot v \cdot f} \cdot\left(1+\frac{q \cdot t_{e} \cdot v^{\frac{1}{m}} \cdot f^{\frac{y}{m}}}{C_{v}^{\frac{1}{m}} \cdot D^{\frac{z}{m}}}\right)\right]
$$

\subsection{Machining constraints}

The mathematical model of the problem is represented by equations (25) - (34):

- parameters bounds

$$
\begin{aligned}
& v \geq v_{\min }, \\
& v \leq v_{\max }, \\
& f \geq f_{\min }, \\
& f \leq f_{\max }
\end{aligned}
$$

- tool life constraints

- cutting force constraint

$$
\begin{aligned}
& T \geq T_{\min }, \\
& T \leq T_{\max }
\end{aligned} ;
$$




$$
f^{y_{F}} \leq \frac{F_{m}}{C_{F} \cdot D^{y_{F}}}
$$

- power constraint

$$
v \cdot f^{y_{M}} \leq \frac{6 \cdot P_{m} \cdot \pi \cdot D}{C_{M} \cdot D^{x_{M}}}
$$

- non-negativity constraints

$$
v>0, f>0 \text {. }
$$

\section{Numerical Results}

For validating the aspects presented above, two case studies were developed.

Case study 1 presents the results regarding the impact of tools replacement in case of machining a piece simultaneously using three drills. The problem data are presented in Table 1.

Table 1. Input data for case study 1

\begin{tabular}{|c|c|c|c|}
\hline$D(\mathrm{~mm})$ & $T(\mathrm{~min})$ & $t_{e}(\mathrm{~min})$ & $C_{t}(\mathrm{EUR})$ \\
\hline 5 & 8 & 1.5 & 0.2 \\
\hline 6 & 9 & 1.5 & 0.22 \\
\hline 8 & 11 & 1.5 & 0.46 \\
\hline \multicolumn{4}{|c}{$k=0.33 \mathrm{EUR} / \mathrm{min} ; \tau=480 \mathrm{~min}$} \\
\hline
\end{tabular}

The aspects approached in Section 3 are applied for the two tools replacement regimes, as follows.

I. Every tool is replaced after its tool life ends. Appling equations (5), (7), (10) it results that the time related to replacing the three tools is $t_{r q}=201.96 \mathrm{~min}$, and the cost of this time is $c_{r \tau}=C_{t o t}^{I}=66.647$ EUR $/ \tau$, in accordance with Table 2 .

Table 2. Results for case study 1

\begin{tabular}{|l|l|l|}
\hline Variable & Regime I & Regime II \\
\hline \multirow{3}{*}{$n_{q}$} & 50.53, for $D=8 \mathrm{~mm}$ & 38.4 \\
\cline { 2 - 2 } & 45.71, for $D=9 \mathrm{~mm}$ & \\
\cline { 2 - 3 } & 38.40, for $D=11 \mathrm{~mm}$ & \\
\hline \multirow{2}{*}{$t_{r q}$} & $75.79 \mathrm{~min}$, for $D=8 \mathrm{~mm}$ & $172.8 \mathrm{~min}$ \\
\cline { 2 - 2 } & $68.57 \mathrm{~min}$, for $D=9 \mathrm{~mm}$ & \\
\cline { 2 - 3 } & $57.60 \mathrm{~min}$, for $D=11 \mathrm{~mm}$ & \\
\hline$c_{r \tau}$ & $66.647 \mathrm{EUR} / \tau$ & 0 EUR/change, for $D=8 \mathrm{~mm}$ \\
\hline $\mathrm{c} \Delta T_{i}$ & - & 0.024 EUR $/$ change, for $D=9 \mathrm{~mm}$ \\
\cline { 3 - 3 } & & 0.125 EUR $/$ change, for $D=11 \mathrm{~mm}$ \\
\hline$c_{T \tau}$ & - & 7,72 EUR $/ \tau$ \\
\hline$C_{t o t}^{I / I I}$ & $66.647 \mathrm{EUR} / \tau$ & $62.75 \mathrm{EUR} / \tau$ \\
\hline
\end{tabular}

II. Tools are all replaced at the same time, according to the minimum tool life. In accordance with equation (6), the time of replacing the three tools is $t_{r q}=172.8 \mathrm{~min}$. The tools of diameter $D=6 \mathrm{~mm}$ and $D=8 \mathrm{~mm}$ present an unused tool life of $0.024,0.125 \mathrm{EUR} / \mathrm{a}$ single change, respectively. The results are presented in Table 2. Considering equation (11), $C_{\text {tot }}^{I I}=62.75 \mathrm{EUR} / \tau$.

Case study 2 approaches the impact of tools replacement upon machining parameters optimisation. The paper presents a comparison between two machining processes: simultaneously machining of five holes using five twist drills having $D=8 \mathrm{~mm}$ and $L=15 \mathrm{~mm}$ and machining a single hole using a twist drill having the same characteristics. It is considered a steel piece. The data are presented in Table 3. 
RECENT, Vol. 22, no. 2(64), 2021

Table 3. Input data for case study 2

\begin{tabular}{|l|l|l|l|}
\hline Parameter & Value & Parameter & Value \\
\hline$q$ & 5 & $y_{F}$ & 0.7 \\
\hline$C_{V}$ & 6.0 & $C_{M}$ & 31 \\
\hline$y$ & 0.6 & $x_{M}$ & 2.0 \\
\hline$z$ & 0.4 & $y_{M}$ & 0.8 \\
\hline$m$ & 0.2 & $\eta$ & 0.8 \\
\hline$f_{\min }$ & $0.08(\mathrm{~mm} / \mathrm{rev})$ & $F_{m}$ & $1300(\mathrm{~N})$ \\
\hline$f_{\max }$ & $0.028(\mathrm{~mm} / \mathrm{rev})$ & $P_{m}$ & $2.9(\mathrm{~kW})$ \\
\hline$T_{\min }$ & $5(\mathrm{~min})$ & $t_{e}$ & $1(\mathrm{~min})$ \\
\hline$T_{\max }$ & $25(\mathrm{~min})$ & $D$ & $8(\mathrm{~mm})$ \\
\hline$C_{F}$ & 61.2 & $L$ & $15(\mathrm{~mm})$ \\
\hline$x_{F}$ & 1.0 & & \\
\hline
\end{tabular}

By solving the mathematical model (25)-(34), the results are presented in Table 4, for the two machining processes.

Table 4. Results for case study 2

\begin{tabular}{|l|l|l|}
\hline Variable & $q=5$ tools & $q=1$ tool \\
\hline$D$ & $8 \mathrm{~mm}$ & $8 \mathrm{~mm}$ \\
\hline$L$ & $15 \mathrm{~mm}$ & $15 \mathrm{~mm}$ \\
\hline$v$ & $15.54 \mathrm{~m} / \mathrm{min}$ & $21.44 \mathrm{~m} / \mathrm{min}$ \\
\hline$f$ & $0.28 \mathrm{~mm} / \mathrm{rev}$ & $0.28 \mathrm{~mm} / \mathrm{rev}$ \\
\hline$T$ & $22 \mathrm{~min}$ & $6 \mathrm{~min}$ \\
\hline$\Delta 1 T_{u}$ & $0.103 \mathrm{~min} /$ piece & $0.074 \mathrm{~min} /$ piece \\
\hline
\end{tabular}

\section{Discussions}

The above aspects highlight that tool replacement influences the productivity as well as the production costs. From this reason the tools replacement strategy is very important. The first example shows that regime II of tools replacement (on tools groups) is more favourable, by $3.897 \mathrm{EUR} / \tau$, where $\tau$ is $480 \mathrm{~min}$. Considering a longer period of time, for example three shifts work $\tau=3 \times 480 \mathrm{~min}$, and one year, regime II became even more efficient. Regarding the tool life, the trend of increasing it must be limited in case of multi-tool machining. For example, in case of the second case study, the tool life of a tool that works in a set of three tools is $T=22$ ( $\mathrm{min}$ ). In accordance with equation (22) it should be $T=30 \mathrm{~min}$. But, due to the constraints of the mathematical model (25)-(34), the tool life increasing was limited and the machining parameters were reduced. Of course, the mathematical model (25)-(34) might be improved, by completion or modification. But, the used mathematical model contains the part regarding the purpose of the present paper. This paper is based on mathematical modelling of the industrial experience, certain recommendations from the literature [10-13], as well as on certain partial results obtained by the author. Regression analysis was used. As regards solving the mathematical models of machining parameters optimisation, literature supplies a series of models [3-10,14-17].

\section{Conclusions}

The following conclusions have resulted from this paper:

- Machining parameters must be very carefully determined in case of multi-tool machining in comparison with single-tool machining;

- The tool life in case of multi-tool machining must be longer then the tool life of the same single tool;

- As a consequence of the previous conclusion, in case of multi-tool processing the machining parameters should be lower (less severe) then in case of the same single tool;

- Special attention must be paid to the tools replacement regimes, in case of multi-tool machining;

- Machining operations must be conceived in such a manner as to use tools having as similar tool lives as possible; 
- It is recommended that tools are replaced on tool groups, considering the shortest tool life;

- Failure to consider the above aspects leads to diminishing the productivity and machining cost increasing.

\section{References}

1. Taylor F.W. (1907): On the Art of Cutting Metals. The American Society of Mechanical Engineers, New York

2. Gilbert W.W. (1950): Economics of machining, machining-theory and practice. American Society of Metals, Cleveland, Ohio, USA

3. Bharathi Raja S., Baskar N. (2010): Optimization techniques for machining operations: a retrospective research based on various mathematical models. International Journal of Advanced Manufacturing Technology, ISSN 0268-3768, eISSN 1433-3015, No. 48, pp. 1075-1090, https://doi.org/10.1007/s00170-009-2351-x

4. Costa A., Celano G., Fichera S. (2011): Optimization of multi-pass turning economies through a hybrid particle swarm optimization technique. International Journal of Advanced Manufacturing Technology, ISSN 02683768, eISSN 1433-3015, No. 53, pp. 421-433, https://doi.org/10.1007/s00170-010-2861-6

5. Gayatri R., Baskar N. (2015): Performance analysis of non-traditional algorithmic parameters in machining operation. International Journal of Advanced Manufacturing Technology, ISSN 0268-3768, eISSN 1433-3015, No. 77, pp. 443-460, https://doi.org/10.1007/s00170-014-6452-9

6. Xu S., Wang Y., Huang F. (2017): Optimization of multi-pass turning parameters through an improved flower pollination algorithm. International Journal of Advanced Manufacturing Technology, ISSN 0268-3768, eISSN 1433-3015, No. 89, pp. 503-514, https://doi.org/10.1007/s00170-016-9112-4

7. Rana P.B., Patel J.L., Lalwani D.I. (2019): Parametric Optimization of Turning Process Using Evolutionary Optimization Techniques-A Review (2000-2016). In: Bansal J., Das K., Nagar A., Deep K., Ojha A. (eds.) Soft Computing for Problem Solving. Advances in Intelligent Systems and Computing, Vol. 817. Springer, Singapore, https://doi.org/10.1007/978-981-13-1595-4 13

8. Sofuoğlu M.A., Çakır F.H., Gürgen S. (2019): An efficient approach by adjusting bounds for heuristic optimization algorithms. Soft Computing, ISSN 1432-7643, eISSN 1433-7479, No. 23, pp. 5199-5212, https://doi.org/10.1007/s00500-018-3327-2

9. Lu K., Jing M., Zhang X., Dong G., Liu H. (2015): An effective optimization algorithm for multipass turning of flexible workpieces. Journal of Intelligent Manufacturing, ISSN 0956-5515, eISSN 1572-8145, No. 26, pp. 831-840, https://doi.org/10.1007/s10845-013-0838-7

10. Ivan N.V., Păunescu T., Udroiu R., Ivan M.C., Găvruş C., Pescaru R, (2010): Tehnologia construcţiilor de maşini. Teorie şi abordări inovative (Machine building technology. Theory and innovative approaches), Vol. 1. Editura Universității Transilvania, ISBN 978-973-598-759-6, Braşov (in Romanian)

11. Picoș C., Pruteanu O., Bohosievici C., Coman Gh., Braha V., Paraschiv D., Slătineanu L., Grămescu T., Marin A., Ionesii V., Toca A. (1992): Proiectarea tehnologiilor de prelucrare mecanică prin așchiere (Design of mechanical machining technologies), Vol. 1. Universitas Publishing House, ISBN 5-362-00970-2, Chişinău

12. Ștețiu G., Oprean C., Lăzărescu I.D., Ștețiu M. (1994): Teoria și practica sculelor așchietoare (Theory and practice of cutting tools), Vol I. University of Sibiu Publishing House, ISBN 973-95604-3-1

13. Stephenson D.A., Agapiou J.S. (2016): Metal Cutting Theory and Practice. 3rd ed., CRC Press, ISBN 9780367868192

14. Cottle R.W., Thapa M.N. (2017): Linear and nonlinear optimization. Springer, New York, USA, pp. 61-228, https://doi:10.1007/978-1-4939-7055-1

15. Mellal M.A., Williams E.J. (2015): Cuckoo optimization algorithm for unit production cost in multi-pass turning operations. International Journal of Advanced Manufacturing Technology, ISSN 0268-3768, eISSN 1433-3015, No. 76, pp. 647-656, https://doi.org/10.1007/s00170-014-6309-2

16. Miodragovic G.R., Dordevic V., Bulatovic R.R., Petrovic A. (2019): Optimization of multi-pass turning and multipass face milling using subpopulation firefly algorithm. Journal of Mechanical Engineering Science, ISSN 09544062, eISSN 2041-2983, No. 233(5), pp. 1520-1540, https://doi.org/10.1177/0954406218774378

17. Ivan N.V., Gavrus C., Oancea Gh. (2018): A new method for establishing the depths of cut for cast iron parts turning. Journal of the Brazilian Society of Mechanical Sciences and Engineering, ISSN 1678-5878, eISSN 18063691, No. 40, https://doi.org/10.1007/s40430-018-1417-9 